\title{
THE INFLUENCE OF EDEMA ON THE CAPACITY OF BLOOD PLASMA TO MODIFY FLUID IMBIBITION BY MUSCLE
}

\author{
BY EDWARD LYON COMPERE
}

(From the Otho S. A. Sprague Memorial Institute and the Pathological Laboratory of the Cook County Hospital, Chicago)

(Received for publication January 13, 1927)

Whether edema is primarily due to changes in the blood or to changes in the fixed tissues is still an open question. Marcel Labbé and P. L. Violle (1) found that a frog's gastrocnemius muscle placed in normal human blood plasma loses from 3 to 4 per cent of its weight during the first few hours, remains constant then for about twentyfour hours, and regains its original weight at about the fortieth hour, while a muscle placed in plasma from an edematous subject, whether the edema is of cardiac, renal, or cardio-renal origin, constantly increases in weight. That this increase of imbibition does not depend upon an increased hydrogen ion concentration of the blood is indicated by their finding that in the plasma of a patient with diabetes and marked acidosis, with $\mathrm{pH}$ of 6.40 and an alkaline reserve of 26 (blood taken immediately after death from diabetic coma) there was a diminution of imbibition. In a diabetic with nephritis, on the other hand, with a $\mathrm{pH}$ of the blood of 7.20 , and an edema highly resistant to treatment, the hydrating action of the plasma on frogs' muscle was much more marked than in other cases. They also found that muscles placed in pleural effusion fluids showed an increase of imbibition. These results support the view that the cause of edema is to be found in the body fluids rather than in the tissues.

The conception that edema is due to changes in the blood is not a novel one. Before the work of Jacques Loeb (2), and the more recent work of Martin Fischer (3) which indicates that the primary cause of edema is to be found in changes within the tissues, the theory supported by Labbé's results was accepted by many workers.

We sought to duplicate the experiments of Labbé and Violle (1). Blood was taken with the precautions necessary for the determination 
TABLE

\begin{tabular}{|c|c|c|c|c|c|c|c|c|c|}
\hline \multirow{2}{*}{$\begin{array}{l}\text { Liquids of immersion, } \\
10^{\circ} \mathrm{C} .\end{array}$} & \multicolumn{9}{|c|}{ Differences of weights in grams per 100 of muscle immersed, after: } \\
\hline & \begin{tabular}{c|}
2 \\
hours
\end{tabular} & $\begin{array}{c}8 \\
\text { hours }\end{array}$ & $\begin{array}{c}17 \\
\text { hours }\end{array}$ & $\begin{array}{c}19 \\
\text { hours }\end{array}$ & $\begin{array}{c}24 \\
\text { hours }\end{array}$ & $\begin{array}{c}36 \\
\text { hours }\end{array}$ & $\begin{array}{c}43 \\
\text { hours }\end{array}$ & \begin{tabular}{|c|}
48 \\
hours
\end{tabular} & $\begin{array}{c}72 \\
\text { hours }\end{array}$ \\
\hline $\begin{array}{c}\text { Chart I } \\
\text { Plasma normal blood }\end{array}$ & & & & & & & & & \\
\hline I A.............. & -2.95 & & & & 1.9 & 11.8 & & & 12.7 \\
\hline I $\mathrm{B}, \ldots \ldots \ldots \ldots \ldots$ & -2.6 & & & & 1.22 & 6.62 & & & 10.4 \\
\hline II $A . \ldots \ldots \ldots \ldots$ & -4.24 & & & & -1.56 & 3.29 & & & 9.0 \\
\hline III A............. & $|-7.94|$ & & & & -5.92 & 3.57 & & & 14.0 \\
\hline $\begin{array}{c}\text { Nephritic. Edema } \\
+++\end{array}$ & & & & & & & & & \\
\hline II B.... & -2.0 & & & & 6.16 & 12.5 & & & 19.0 \\
\hline III B.... & -6.1 & & & & -0.88 & 10.0 & & & 15.0 \\
\hline IV A............. & -1.7 & & & & 10.6 & 15.4 & & & 21.0 \\
\hline IV $B . \ldots \ldots \ldots \ldots$ & -2.8 & & & & 8.86 & 14.7 & & & 16.9 \\
\hline Chart II & & & & & & & & & \\
\hline Plasma normal blood & & & & & & & & & \\
\hline VA $\ldots \ldots \ldots \ldots$ & & -4.9 & & & -1.9 & & & & 5.0 \\
\hline VI A............ & -2.8 & & 2.3 & 2.2 & & & & 7.4 & 8.1 \\
\hline VI $B, \ldots \ldots \ldots$ & -3.3 & & -1.2 & -0.9 & & & & 7.4 & 9.0 \\
\hline Cardiac. Edema & & & & & & & & & \\
\hline $\mathrm{v} B \ldots \ldots \ldots$ & & -3.4 & & & 5.0 & & & & 7.0 \\
\hline VII $A \ldots \ldots \ldots$ & -5.9 & & -2.2 & -2.0 & & & & 9.4 & 12.3 \\
\hline VII $B \ldots \ldots \ldots \ldots$ & -3.9 & & 5.8 & 6.2 & & & & 13.0 & 14.5 \\
\hline Chart III & & & & & & & & & \\
\hline Iodine poisoning & & & & & & & & & \\
\hline No edema & & & & & & & & & \\
\hline VIII A......... & -2.3 & & & & 4.1 & & & 12.7 & 14.9 \\
\hline VIII B........... & -2.4 & & & & 2.0 & & & 11.7 & 13.0 \\
\hline $\operatorname{IX} \mathrm{A} \ldots \ldots \ldots \ldots$ & -1.4 & & & & 5.3 & & & 8.7 & 12.5 \\
\hline $\mathrm{x} A \mathrm{~A}, \ldots \ldots \ldots \ldots$ & -3.9 & & & & 3.7 & & & 7.3 & 9.8 \\
\hline $\begin{array}{c}\text { Cardiac decompensa- } \\
\text { tion. Edema } \\
++++\end{array}$ & & & & & & & & & \\
\hline IX $\mathrm{B}, \ldots \ldots \ldots \ldots$ & -4.9 & & & & -2.6 & & & 6.6 & 10.6 \\
\hline $\mathrm{X} B \ldots$ & -1.2 & & & & 6.7 & & & 11.0 & 15.7 \\
\hline $\begin{array}{c}\text { Chart IV } \\
\text { Cardiac decompensa- } \\
\text { tion. Edema } \\
+++\end{array}$ & & & & & & & & & \\
\hline XI A............ & -6.9 & & & & -5.5 & & & -3.8 & 4.2 \\
\hline XI B........... & -7.8 & & & & -7.26 & & & -1.3 & 6.3 \\
\hline Cardiac decompensa- & & & & & & & & & \\
\hline XII A........... & -5.17 & & & & -1.15 & & & 1.38 & 1.9 \\
\hline XII B............ & -6.6 & & & & -4.6 & & & -1.4 & 2.8 \\
\hline
\end{tabular}


TABLE 1-Continued

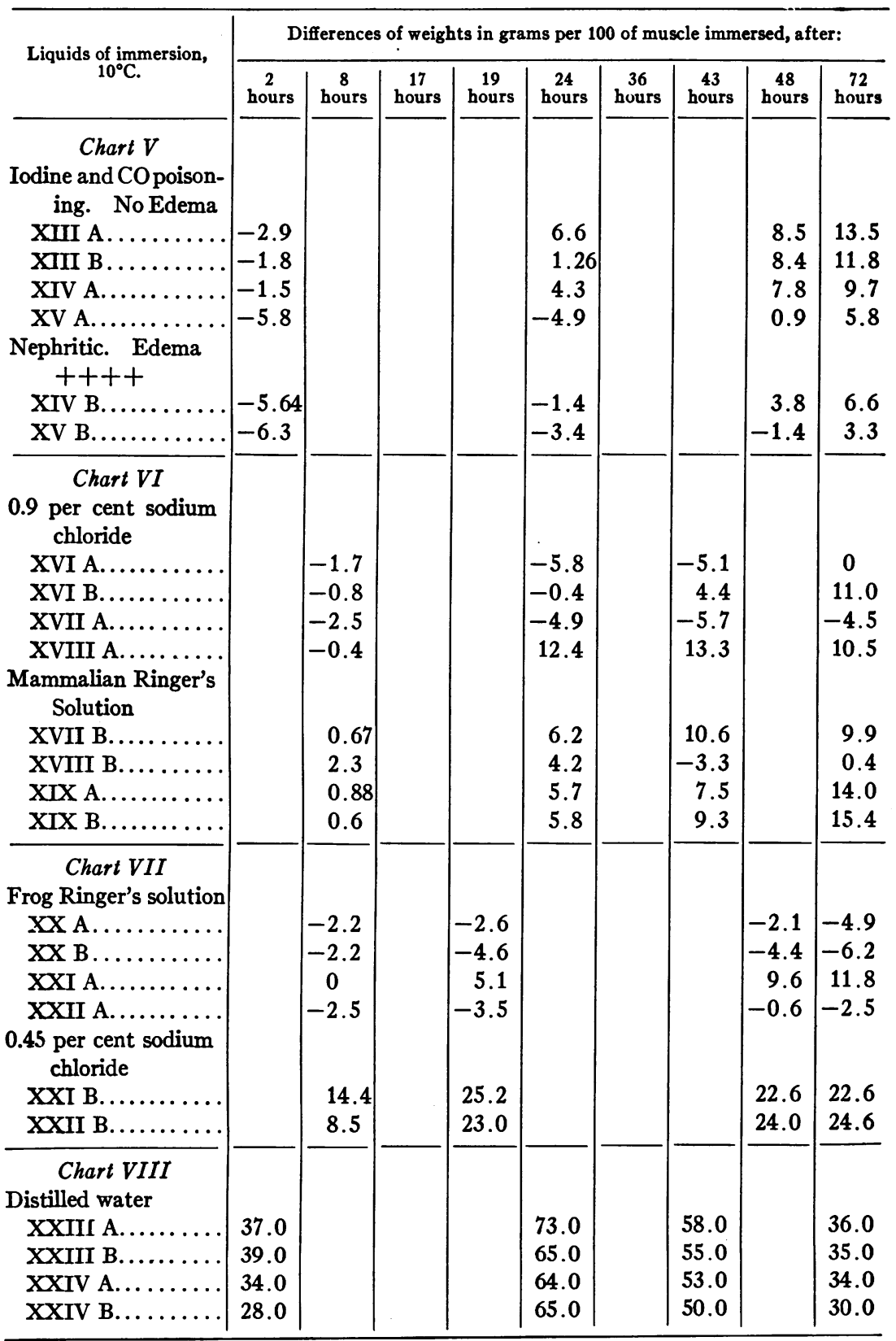


TABLE 1-Contınued

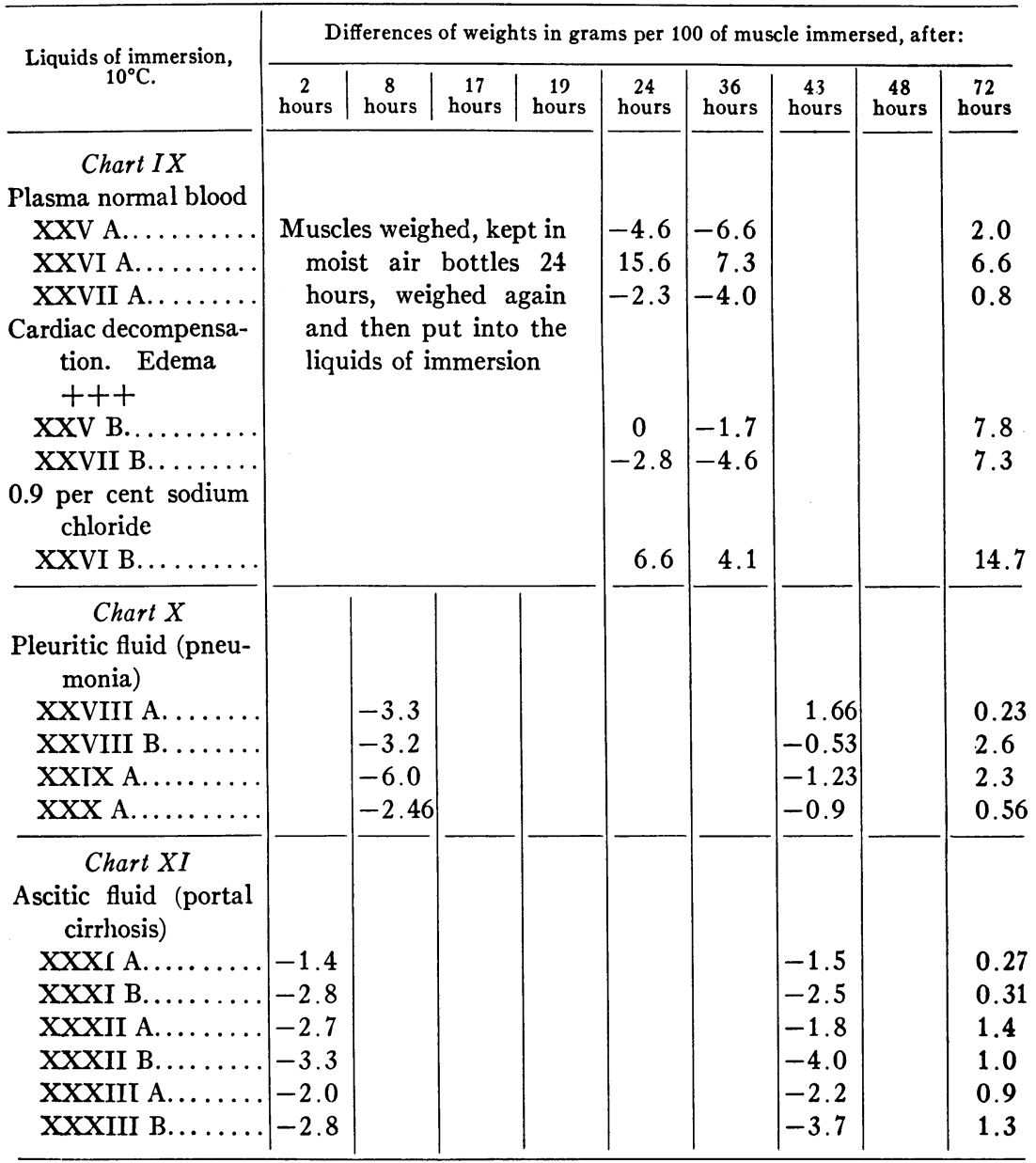

of blood $\mathrm{pH}$, and the plasma was kept covered by a layer of paraffin oil and at a temperature of $8^{\circ}$ to $12^{\circ} \mathrm{C}$. In order to check our results we took two liquids of immersion at the same time, as, for example, plasma from a patient with no edema or condition commonly associated with edema, and plasma from a patient with severe edema. Into portions of the plasma from the edematous subject we put both gastrocnemii of one frog; into the other plasma we immersed both muscles of a second frog. We then took a third frog or a third and a 
fourth frog and immersed one muscle of each in each of the two kinds of plasma. By repeatedly immersing, drying and weighing the muscles of a frog, we found that we were able to perfect a technique which

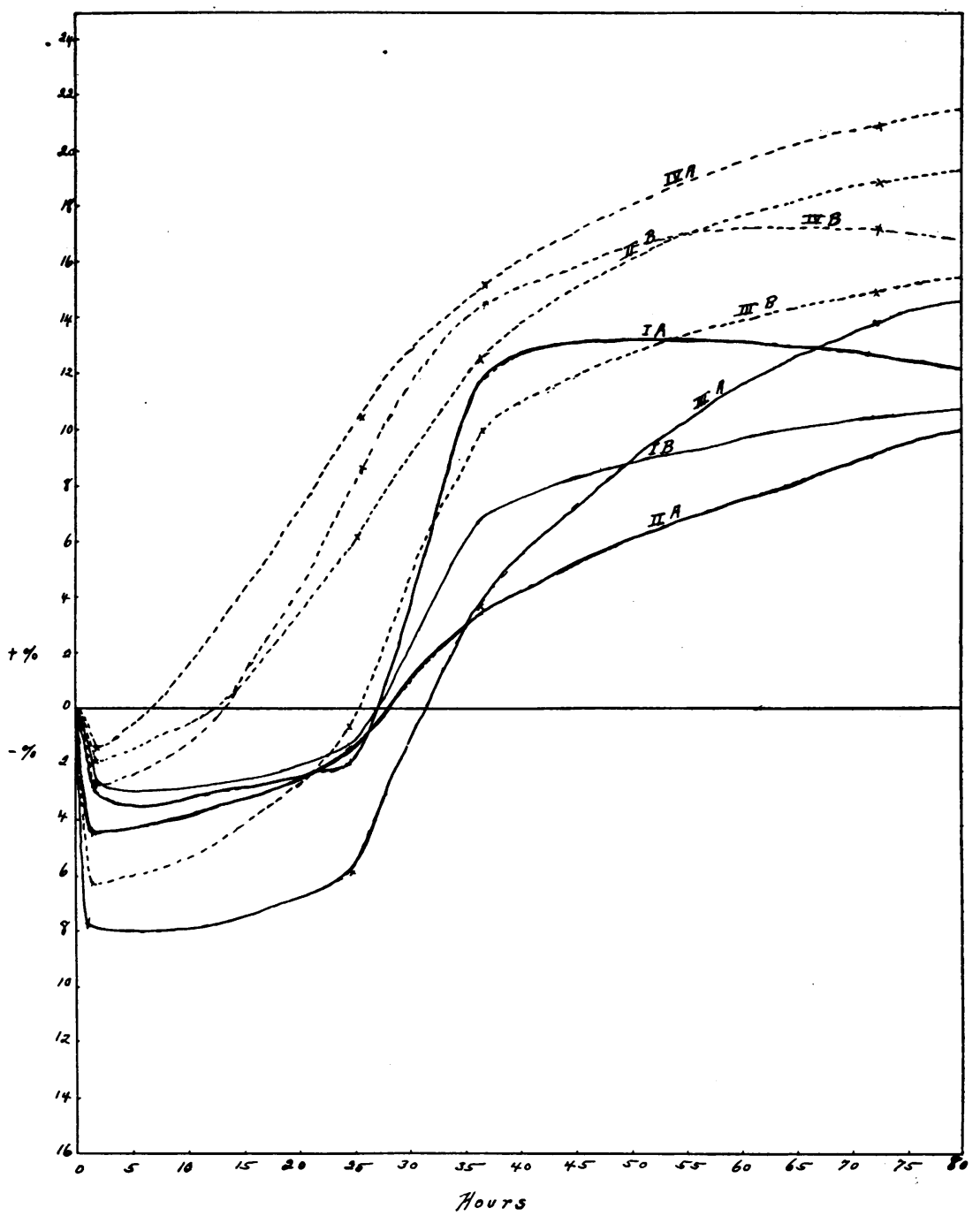

\section{Chart I}

Plasma normal blood.

Plasma from patient with nephritis and edema +++ . 
involved an error of less than 2 per cent attributable to adherent plasma.

The results of the experiments are given in table 1 and are repre-

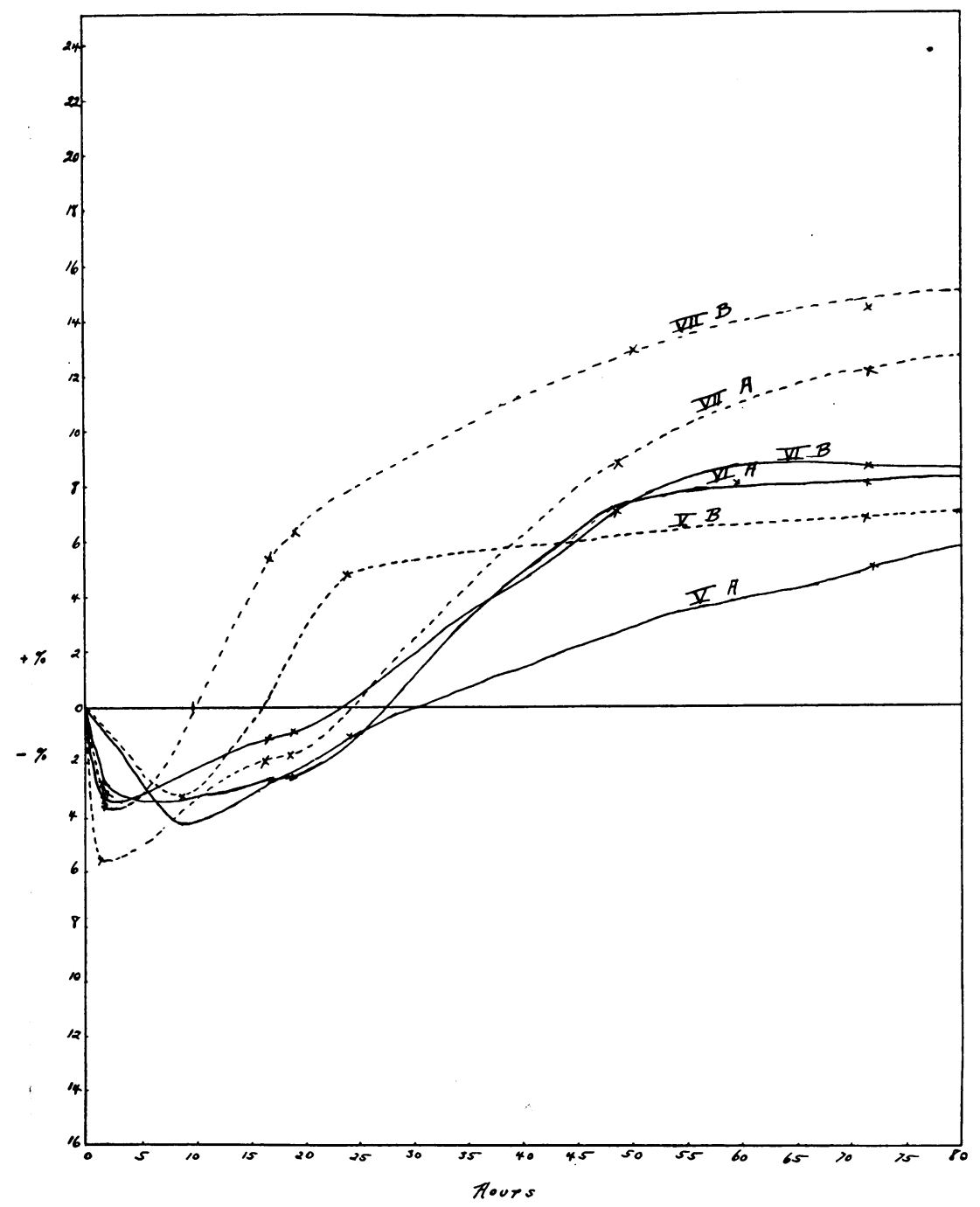

Chart II

_ Plasma normal blood.

-.... Cardiac decompensation and edema +++ . 
sented graphically in the charts in which the Roman numerals indicate individual frogs, and the letters $\mathrm{A}$ and $\mathrm{B}$ the two gastrocnemii of the same frog.

The curves in charts I and II at first glance would seem to indicate that imbibition is greater in muscles placed in plasma from edematous patients than in plasma from non-edematous subjects, as Labbé and Violle had reported; yet the striking differences in the curves of two muscles of different frogs in the same plasma (IV A and III B; VII B and $\mathrm{V} \mathrm{B}$ ) and of two muscles of the same frog in the same plasma (I A and I B; VII A and VII B) casts some doubt on the correctness of attributing differences in amount of imbibition solely to differences in the plasma. This doubt is further strengthened by the evident tendency of the curves of muscles of the same frog to approximate each other regardless of the type of plasma of immersion (III A and III B, VI A and VI B, V B and V A; also in charts III and IV).

We invariably found an initial loss of weight of muscles placed in plasma whether from edematous or non-edematous patients, thus differing from Labbé and Violle who found no initial loss of weight in muscles placed in plasma from edematous subjects. The initial loss of weight occurred whether or not the muscles were cooled to $10^{\circ} \mathrm{C}$. To eliminate also a possible error which might result from blood adhering to the muscles being washed off in the plasma between the first and second weighings and thus causing the loss of weight, the muscles were dipped in the plasma and dried thoroughly before the first weighings.

Chart I represents the curves of muscles in plasma from a patient without edema and from one with severe edema. The curves of imbibition are preceded by curves of dehydration which show a precipitous drop. The curves then rise gradually toward the base line, and, as is true in all of the charts of muscles immersed in plasma, the rise of the curves above the base line is much less abrupt than is the initial drop. The curves for the muscles from frogs I, III, and IV seem to be influenced as much by the origin of the muscle from a particular frog as by the type of plasma in which it is immersed. Curves A and B of frog II, however, are widely separated, the greater imbibition being in muscle II B in the plasma from the edematous patient.

The results noted in chart II are very similar to those of chart I. 
The increase in weight is greatest in muscles A and B of frog VII which were placed in the plasma of a patient with severe edema on a cardiac basis. The greatest initial loss of weight is also in one of these

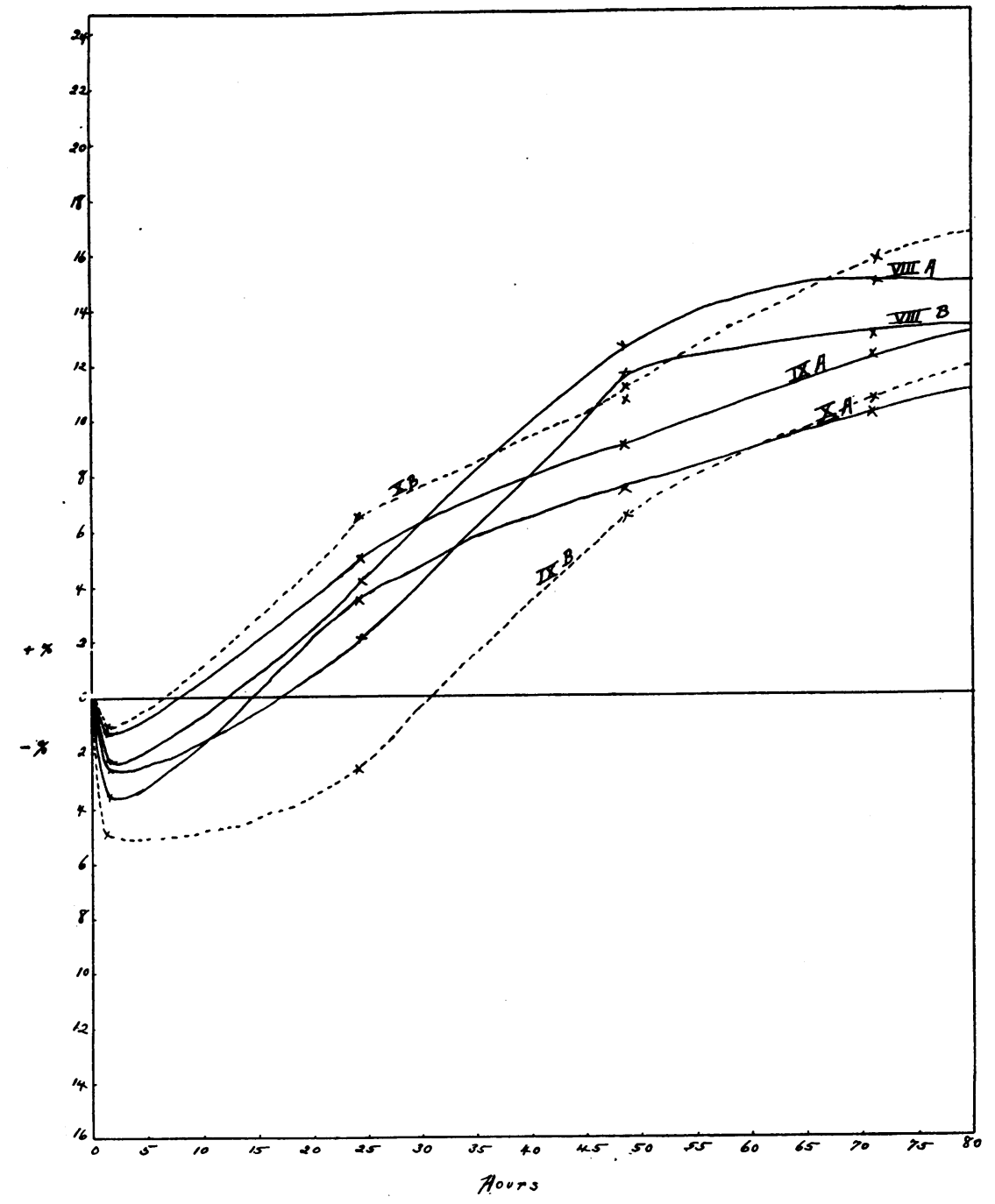

Chart III

Plasma from patient suffering from iodine poisoning. No edema.

Plasma from patient with cardic decompensation and edema ++++ . 
muscles (VII A). Here again it is seen that the curves of the two muscles of each frog exhibit a tendency to approximate each other. The greatest variation between two muscles of the same frog is noted for the muscles of frog $\mathrm{V}$, which were in different kinds of plasma. But even in this case the dehydration curves of the two muscles and the imbibition curve from 45 to 75 hours are very similar.

Chart III illustrates the curves of muscles placed in plasma from a patient with iodine poisoning and with no edema or history of cardiac or renal disease, and curves of muscles in plasma from a patient with extremely severe edema and cardiac decompensation. The curves for muscles IX B and X B both in plasma from the edematous patient, illustrate the danger of concluding that the amount of imbibition depends solely upon the plasma, since at the twenty-fourth hour of immersion muscle X B shows the greatest, and muscle IX B the least gain in weight of any muscle in the experiment represented on chart III. At the forty-eighth hour the greatest increase in weight is of muscle VIII $A$ in the plasma of the non-edematous patient. While curves or the two muscles of frog VIII follow each other closely, those of the muscles of the other two frogs show greater differences.

In chart IV is seen a comparison between the rate of imbibition of muscles in plasma from a patient with slight pitting edema, and from one with severe edema. The greatest initial loss of weight is noted in the two muscles of frog XI which were in the plasma of the patient with the greater edema. The curves of these however cross those of the muscles XII A and XII B, which were immersed in plasma from the patient with the lesser edema, in from 45 to 65 hours.

The futility of attaching any great significance to results which might indicate that the rate of imbibition is dependent solely upon the presence of edema in the individual from whom the plasma was taken, may be seen by a comparison of chart V with charts I and II, for chart $\mathrm{V}$ represents almost opposite results from those in charts I and II. Three of the muscles (XIII A, XIII B, and XIVA) in the plasma from patient with no edema show greater imbibition than either of the muscles immersed in the plasma of the patent with the severe edema. As further evidence of inconsistency of results as interpretable on a basis of differences in plasma, the curve of muscle XV A is not only considerably lower than that of any other muscles in the same plasma, 
but at the twenty-fourth hour of immersion it is lower than any other curve regardless of plasma. Later the curve crosses that of the other muscle of the same frog which was in the plasma of the non-edematous

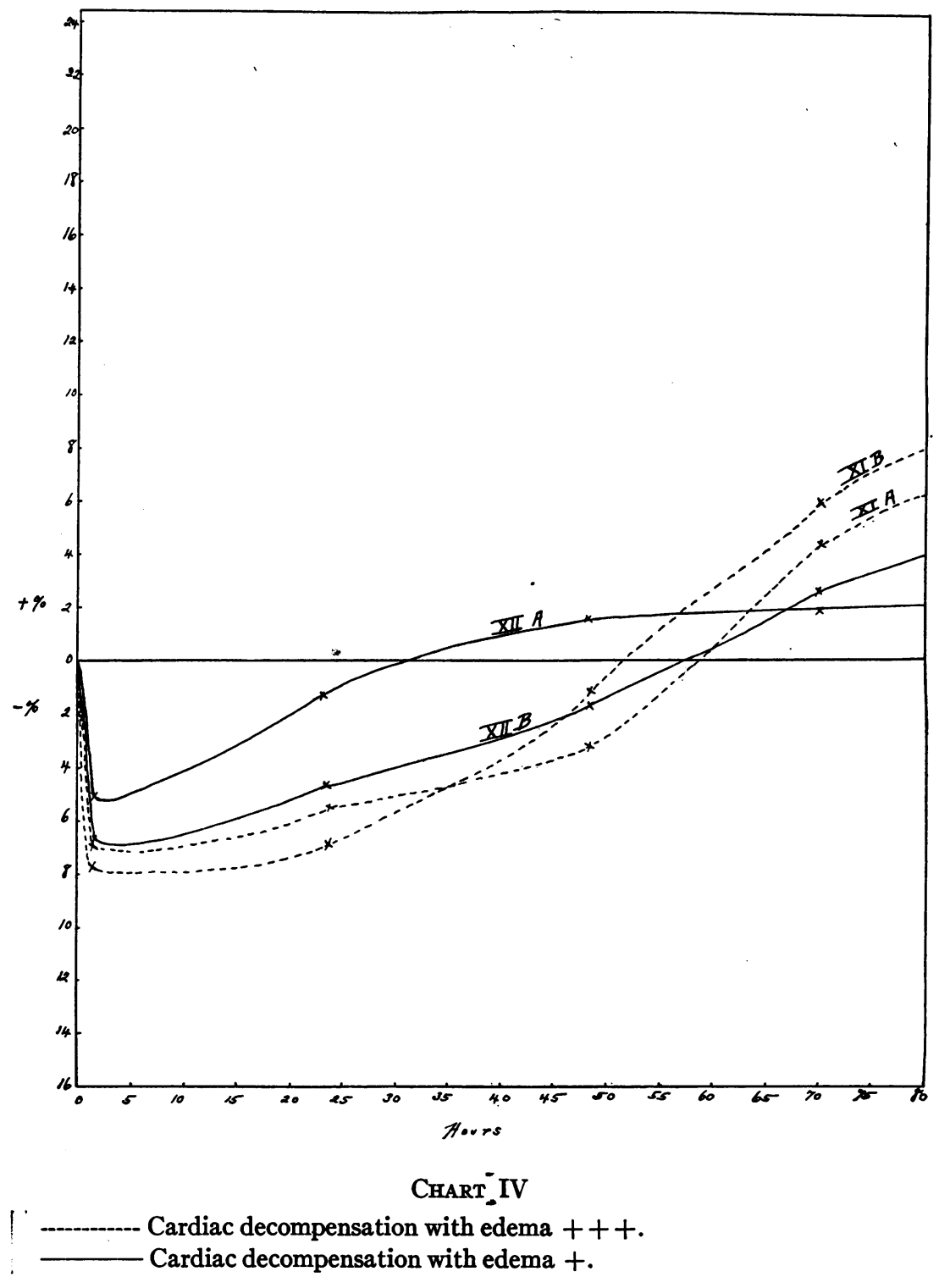


patient. Here again the curves of the two muscles of each frog tend to approximate each other, regardless of the plasma into which they were immersed.

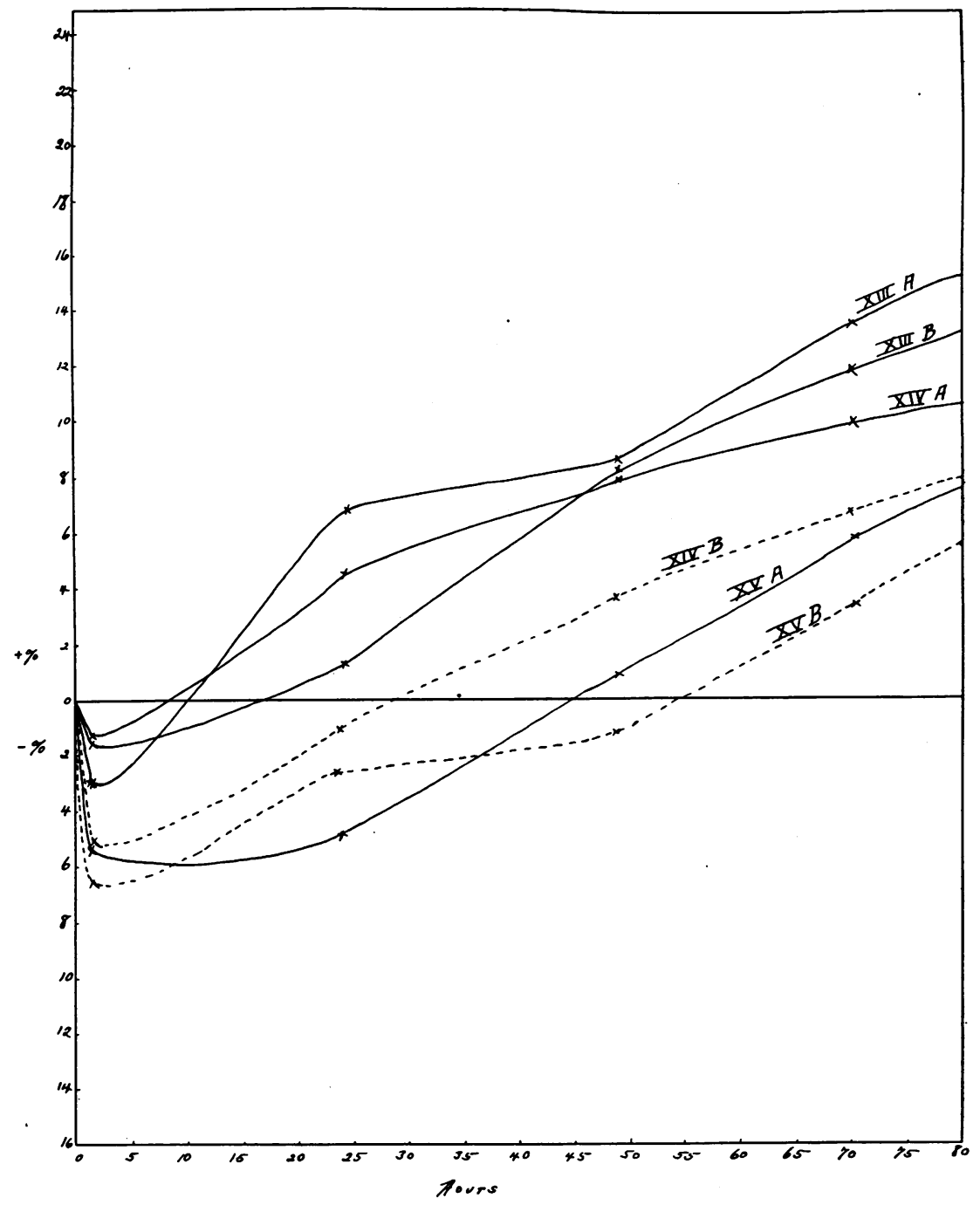

Chart V

Iodine and $\mathrm{CO}$ poisoning case. No edema.

Plasma of patient with severe nephritis and edema ++++ . 
Martin Fischer (4), in his book on Edema and Nephritis, suggests that the imbibition of fluid by tissues, as seen in the certain edemas, may be due to lack of oxidation in the tissues. Since carbon-monoxide

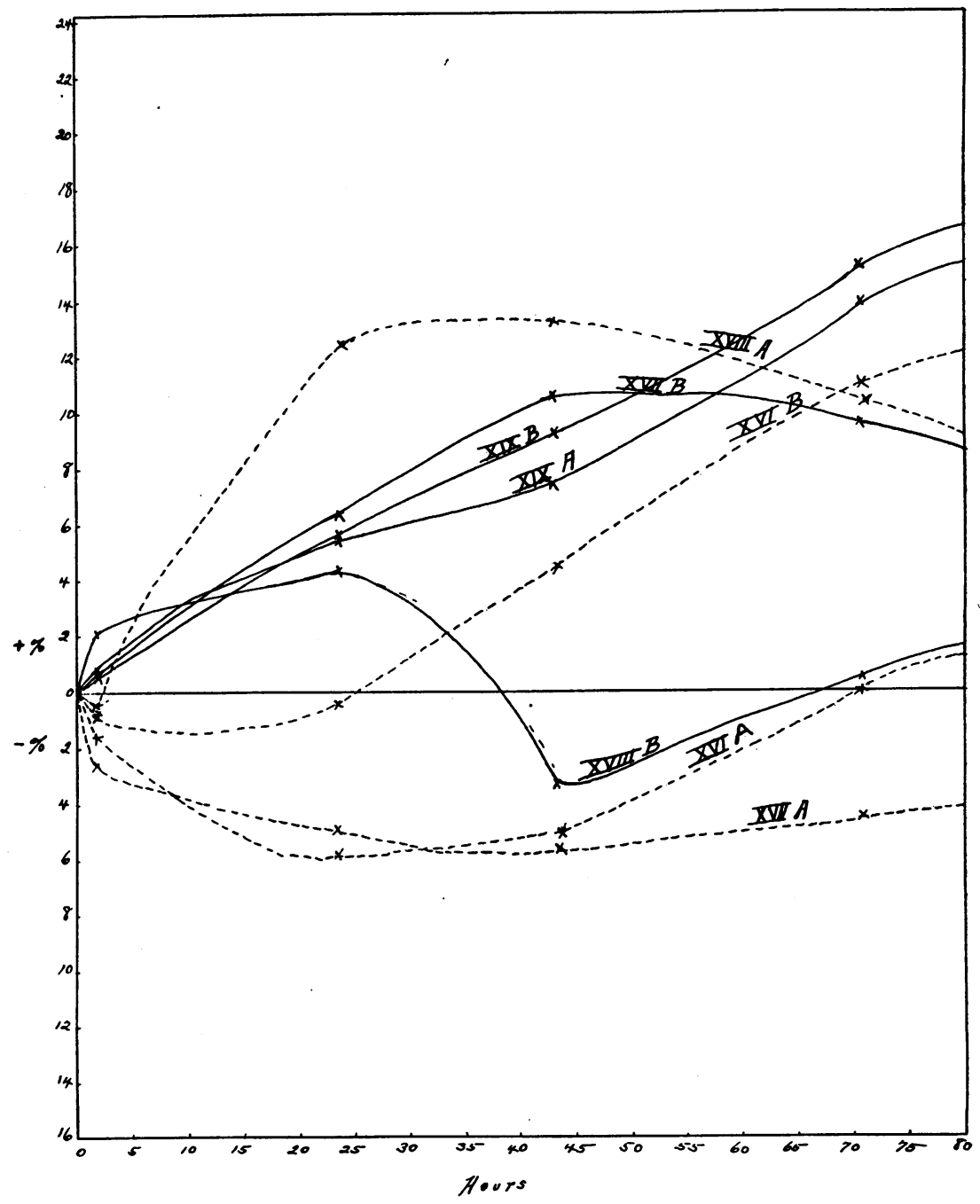

Chart VI

0.9 per cent sodium chloride solution

Mammalian Ringer's solution. 
poisoning is a condition in which the oxygen supply to the tissues is reduced, one might be led to believe that imbibition by the muscles in the plasma of the patient with carbon-monoxide poisoning (chart V) may have been influenced by this condition. On the other hand it is to be remembered that even in severe cases of carbon-monoxide poisoning, edema is never a directly associated finding. Also it may be noted, by comparison with the previous Charts, that the curves of the muscles in this plasma are no higher than many of the curves of muscles in plasma of other controls. The striking point in this chart and in some of the others discussed, is the low rate of imbibition by muscles in the plasma of a patient with marked edema.

Chart VI represents the imbibition curves of muscles placed in 0.9 per cent sodium chloride solution and in mammalian Ringer's solution. This chart illustrates very well the danger of attributing great significance to any results such as those reported by Labbé and Violle, or as previously seen in charts I to $\mathrm{V}$. All of the muscles placed in 0.9 per cent salt solution lost weight during the first hour, while all of those placed in the mammalian Ringer solution imbibed fluid from the time of immersion. The rate of imbibition of muscle XVIII A in the sodium chloride solution is greatest, while the secondary dehydration of muscle B of the same frog, which was immersed in mammalian Ringer solution, we cannot explain. The crossing of the imbibition curves of muscles in the same and in different solutions causes one to hestiate to attribute any specific significance to the results previously discussed. The marked difference between the amounts of imbibition of the two muscles of frog XVI, in the identical solution, would indicate that slight differences in imbibition of muscles in different kinds of plasma may not safely be attributed to differences in the plasma.

That the rate of imbibition by the muscles depends to a large extent upon the state of isotonicity of the solution into which it is immersed, is indicated in charts VII and VIII. The curves for the muscles XXI $\mathrm{B}$ and XXII B in 0.45 per cent sodium chloride solution, which is hypotonic to frog's blood or plasma, show no dehydration but a marked imbibition beginning at once upon immersion. Three of the muscles in the frog Ringer's solution, which is nearly isotonic to frog fluids, lost weight during the first two hours, and did not regain their 
initial weight during the entire 72 hours of immersion. Muscle XXI A, however, in the same solution showed no change of weight during the first 2 hours and then gained weight, gradually, but steadily,

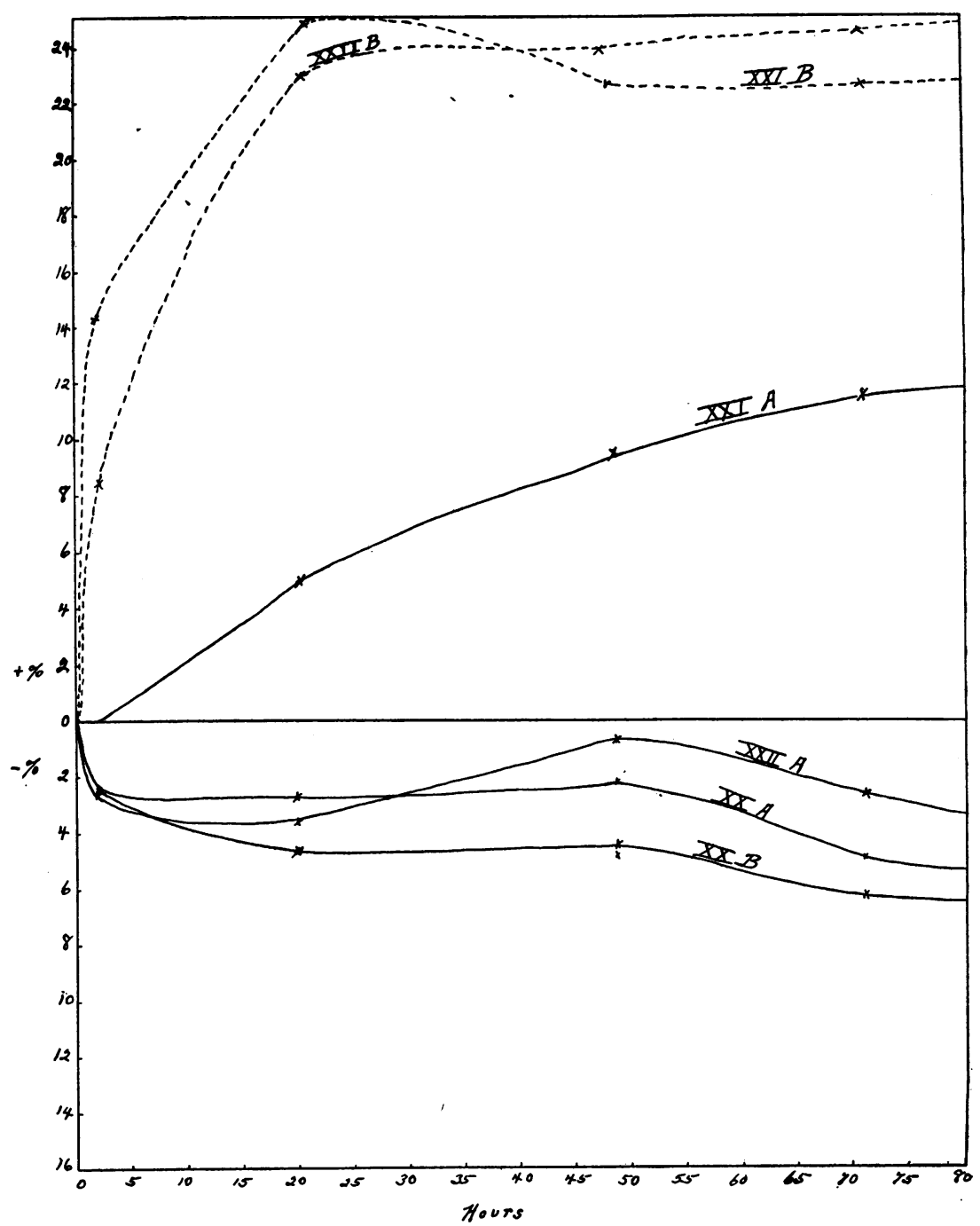

\section{Chart VII}

Frog Ringer's solution.

0.45 per cent sodium chloride solution. 
during the subsequent 70 hours, a variation for which we can offer no satisfactory explanation. When the muscles of several frogs were

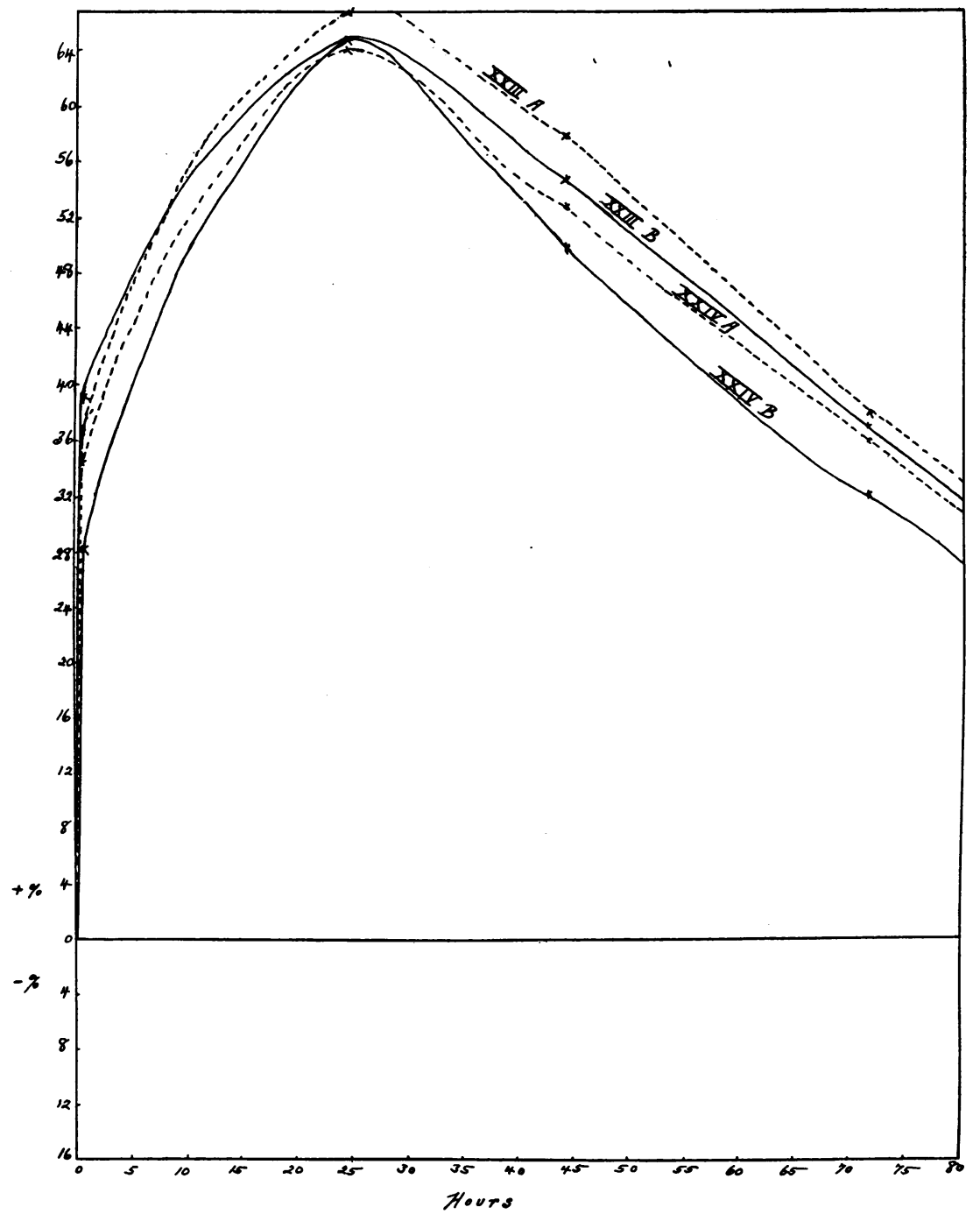

Chart VIII. Distifled Water

placed in sterile water at $10^{\circ} \mathrm{C}$. (chart VIII), all imbibed fluid very rapidly from the time of immersion, increasing in weight from 28 to 
34 per cent during the first hour, and from 64 to 73 per cent during the first 24 hours. The curves for all of the muscles are strikingly

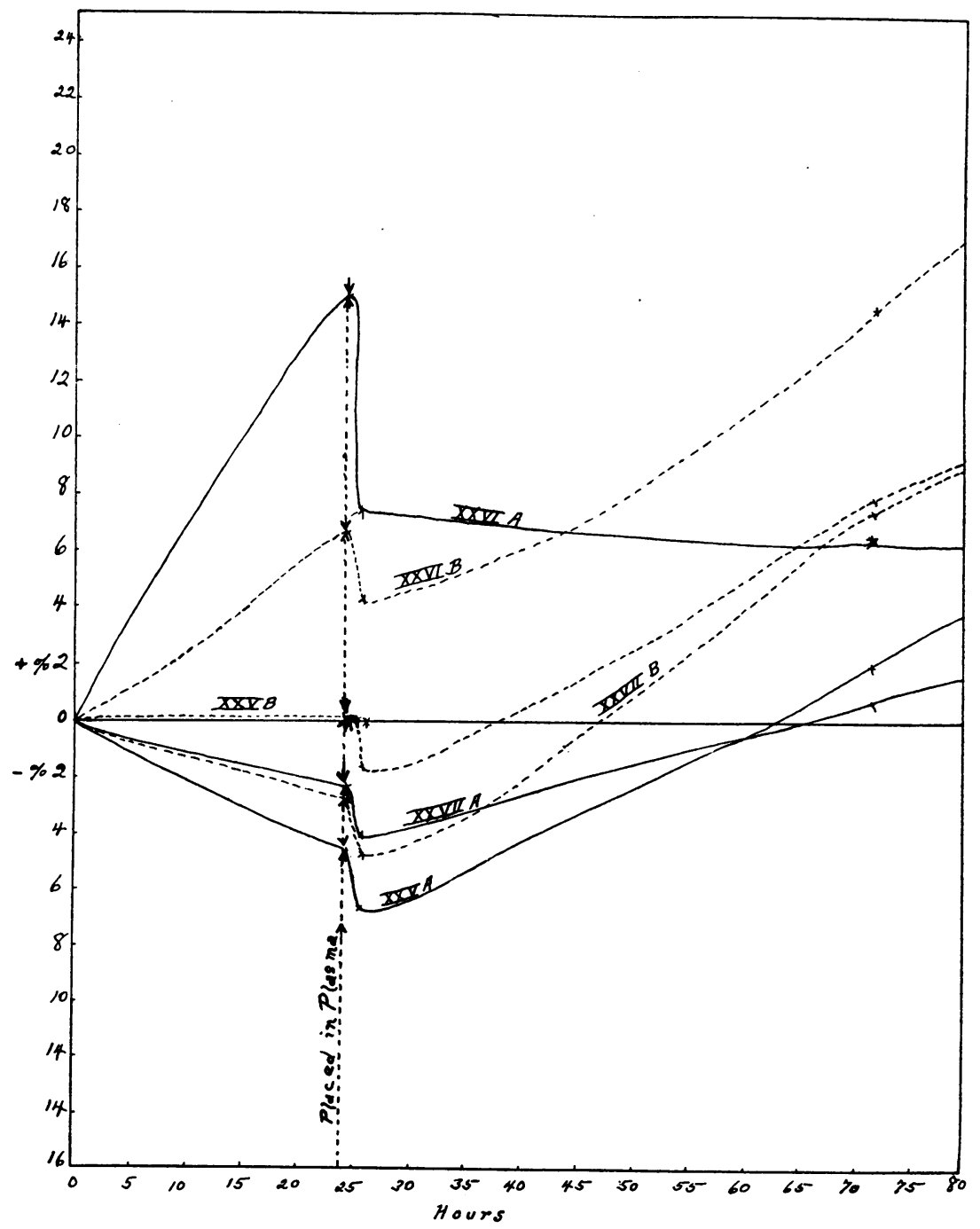

Chart IX

Plasma normal blood.

Cardiac decompensation. Edema +++ .

XXVI B ------- 0.9 per cent sodium chloride solution. 
similar, both in showing a rapid increase in weight of the muscles and a more gradual loss in weight after the first 24 hours.

To test out the possibility suggested by the work of Martin Fischer (3), that imbibition by the muscles may be influenced by the production of acid products in them due to degeneration after removal from the frogs, we removed the gastrocnemii from a number of frogs and kept them in moist air in bottles for 24 hours before immersing them in the various fluids (see chart IX). The increase in weight of some of the muscles (XXVI A and XXVI B) while in the bottles may have been due to an excess of moisture in the bottles. The immediate dehydration which occurred with immersing the muscles in the fluids is striking. During the 24 hours, degenerative changes must have taken place, but instead of immediately imbibing fluid from the plasmas or salt solution all muscles lost weight when first immersed. As all of the fluids of immersion were hypertonic to frog plasma, and as we have seen in previous charts that muscles placed in hypotonic solutions immediately imbibe fluid, a phenomenon which may be explained on a basis of osmosis, without initial dehydration, we are inclined to consider the initial loss in weight seen in chart IX as largely a matter of osmosis, but the subsequent imbibition is not so easily explained.

Labbé and Violle reported that frog muscles placed in the fluid of pleural effusion without regard to the etiology of the condition. also showed an increased power to take up fluid. We were entirely unable to corroborate this finding. In experiments in which we placed frog muscles in fluid of pleural effusions, the initial loss in weight was very similar to that seen when the muscles were placed in the blood plasma of the various types of patients, but the subsequent imbibition was very gradual, and at the end of 72 hours the muscles had increased in weight only from 0.3 to 2.5 per cent above their original weight. Although we tried this in a number of cases, our results were always similar to those illustrated in chart X.

Chart XI represents the imbibition curves of frog muscles placed in fluid taken from the abdominal cavity of a patient with portal cirrhosis of the liver. The curves are seen to be very similar to those in the pleural effusion fluid. 
270

INFLUENCE OF EDEMA ON IMBIBITION

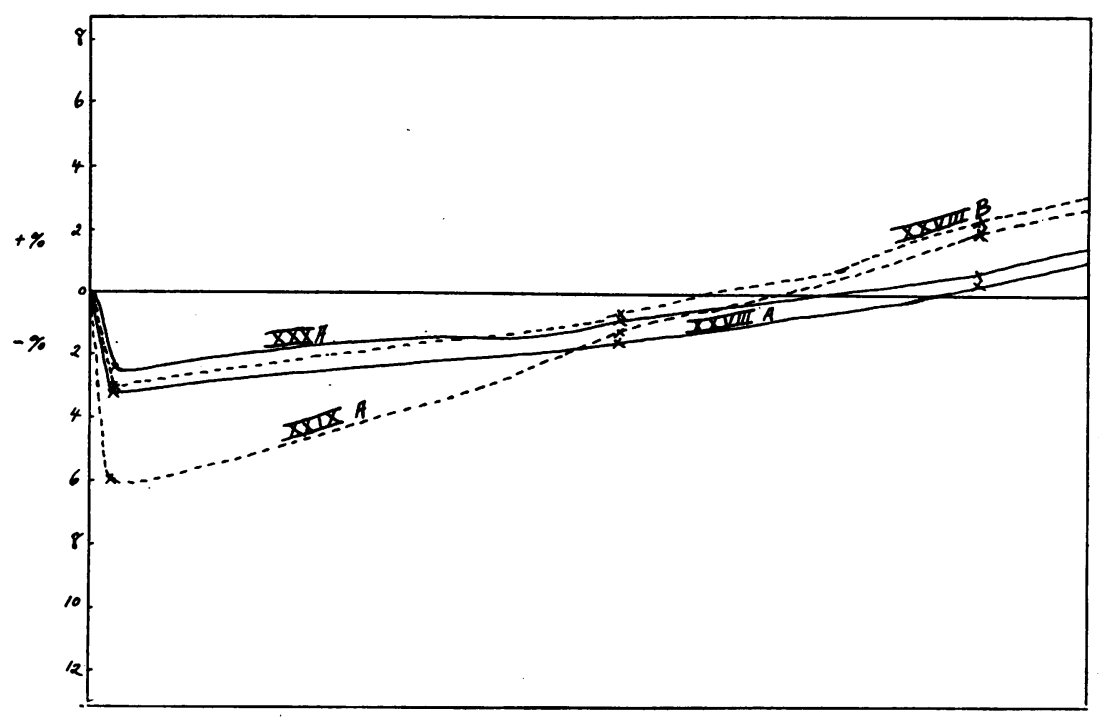

Chart X. Fum from Pleural Cavity (Pneumonia)

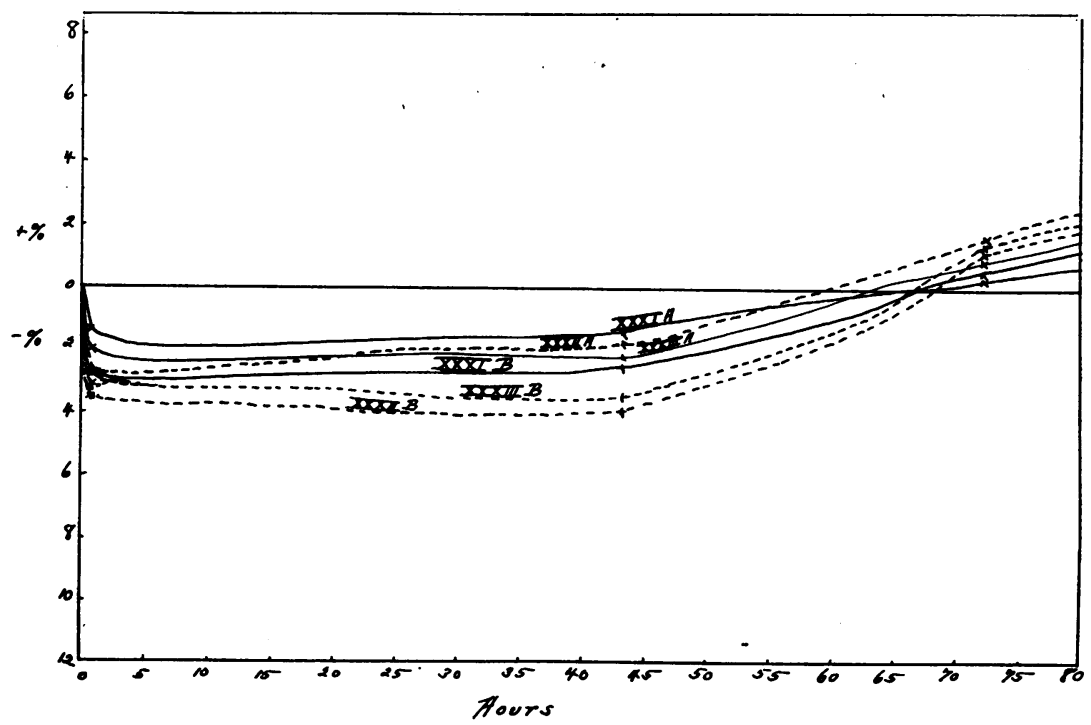

Chart XI. Fluid from Abdominal Cavity (Portal Cirrhosis) 


\section{SUMMARY}

Experiments, in which the rate of imbibition by frog muscles immersed in the plasma of edematous and non-edematous patients and in various other fluids was studied, were carried out with the following results.

1. An initial loss of weight occurred in all frog muscles placed in blood plasma at $10^{\circ} \mathrm{C}$. regardless of whether that plasma was taken from a subject with edema or with no edema. This initial dehydration was, in some instances, greater in muscles placed in plasma from an edematous subject than in those placed in plasma of a subject without edema.

2. Although in some instances muscles placed in plasma of edematous subjects increased in weight more rapidly than did muscles in normal plasma, this was not a constant finding, since at times a muscle in normal plasma increased in weight more rapidly than did a second muscle of the same frog or a muscle of a different frog in the plasma of a patient who had a very marked edema.

3. The imbibition curves of the muscles in the various specimens of plasma were too variable to permit of drawing any conclusions as to the influence of any particular type of plasma upon imbibition.

4. In hypotonic salt solution frogs muscles showed marked imbibition without initial dehydration, while in hypertonic solutions there was an initial dehydration with subsequent slight or moderate imbibition.

5. There was a tendency in most instances for the two muscles of the same frog to imbibe fluid at approximately the same rate, without regard to the fluid of immersion. This was not a constant finding, for in several instances there was a considerable difference in the rates of imbibition of two muscles of the same frog in plasma from the same individual, whether that individual had edema or not.

6. Frog muscles immersed in the fluid of pleural effusion, such as resulted from pneumonia, or fluid from the abdominal cavity of a patient with cirrhosis of the liver with portal obstruction, lost from 1 to 6 per cent of their weight during the first 1 or 2 hours, and very slowly regained their original weight in from 45 to 65 hours.

7. The results of these experiments do not support the theory that 
edema depends upon changes in the blood of such a nature that they increase the imbibition of fluid by the tissues bathed by this blood.

\section{BIBLIOGRAPHY}

1. Labbé, Marcel, and Violle, P. L., Compt. rend. Soc. de Biol., 1925, xcii, $963 . \quad$ Action Hydratante (Exercée sur le Tissue Musculaire) du Plasma et des Sérosités des Sujets Oedématiés.

2. Loeb, Jacques, Arch. f. d. ges. Physiol., 1898, lxix, 1, Physiologische Untersuchungen über Ionenwirkungen. I. Versuche am Muskel. Ixxi, 457, Physiologische Untersuchungen über Ionenwirkungen. II. lxxv, 303, Ueber die Aehnlichkeit der Flüssigkeitsresorption in Muskeln und in Seifen.

3. Fischer, Martin H., Edema and Nephritis. New York, 1921, p. 220-262.

4. Fischer, Martin H., Edema and Nephritis. New York, 1921, p. 262-276. 